\title{
Age- and sex-dependent mRNA expression of KCNQ1 and HERG in patients with long QT syndrome type 1 and 2
}

Ewa Moric-Janiszewska1, Joanna Głogowska-Ligus², Monika Paul-Samojedny³, Ludmiła Węglarz'1, Grażyna Markiewicz-Łoskot ${ }^{4}$, Lesław Szydłowski

\author{
1Department of Biochemistry, Medical University of Silesia, Sosnowiec, Poland \\ 2Department of Epidemiology, Medical University of Silesia, Bytom, Poland \\ ${ }^{3}$ Department of Medical Genetics, Medical University of Silesia, Sosnowiec, Poland \\ 4Department of Nursing and Social Medical Problems, Medical University of Silesia, \\ Katowice, Poland \\ ${ }^{5} 1^{\text {st }}$ Department of Paediatric Cardiology, Medical University of Silesia, Katowice- \\ Ligota, Poland
}

Submitted: 14 October 2010

Accepted: 9 November 2010

Arch Med Sci 2011; 7, 6: 941-947

DOI: 10.5114/AOMS.2011.26604

Copyright (C 2011 Termedia \& Banach

\section{Abstract}

Introduction: The main goal of this study was to examine the patient age and sex dependent expression of KCNQ1 and HERG genes that encode potassium channels responsible for the occurrence of long QT syndrome (LQTS).

Material and methods: The study enrolled 43 families whose members suffered from LQTS type 1 (LQTS1) or 2 (LQTS2) or were healthy. The study attempted to prove that $\beta$-actin is a good endogenous control when determining the expression of the studied genes. Examination of gene expression was achieved with quantitative real-time PCR (QRT-PCR). Expression of the investigated genes was inferred from the analysis of the number of mRNA copies per $1 \mu \mathrm{g}$ total RNA isolated from whole blood.

Results: Significantly lower KCNQ1 and KCNH2 mRNA levels in healthy females than healthy males were observed $(p=0.032 ; p=0.02)$. In male patients both transcripts were expressed at a lower level ( $p=0.0084 ; p=0.035)$. The comparison of transcriptional activity of $\mathrm{KCNQ} 1$ and $\mathrm{KCNH} 2$ in healthy adults and children revealed higher KCNQ1 and lower $\mathrm{KCNH} 2$ mRNA levels in healthy adults $(p=0.033 ; p=0.04)$, higher KCNQ1 and lower KCNH2 mRNA levels in adult patients below 55 years old than in adults over 55 years old $(p=0.036$; $p=0.044$ ), and significantly higher KCNQ1 and lower KCNH2 mRNA levels in adult patients (over 55 years) than in paediatric patients (below 15 years) $(p=0.047 ; p=0.08)$.

Conclusions: The results support the hypothesis that KCNQ1 and HERG gene expression is influenced by age and gender in human patients with long QT syndrome and in healthy subjects.

Key words: long QT syndrome, KCNQ1 gene, HERG gene, expression, potassium channel.

\section{Introduction}

Genetic disorder is an important cause of sudden cardiac death (SCD) in children without structural heart diseases [1, 2]. However, the risk in affected patients is not uniform because of variable penetrance and is influenced by age, gender, genotype, environmental factors, therapy, and possibly other modifier genes [3]. In recent years, numerous advances have been made in the identification of the genotype-phenotype relationship and risk factors for cardiac events in long QT syndrome (LQTS) patients [1, 4-10].

\author{
Corresponding author: \\ Ewa Moric-Janiszewska PhD \\ Department of Biochemistry \\ Medical University of Silesia \\ Narcyzów 1 \\ 41-200 Sosnowiec, Poland \\ Phone: +48 323641006 \\ E-mail: \\ ejaniszewska@sum.edu.pl
}


Hereditary long QT syndrome (LQTS) is characterized by prolonged ventricular repolarization on the ECG and arrhythmia-related syncope and sudden death [3, 11-13]. Mutations in several ion channel genes are known to cause this disorder [14], mutations in the KCNQ1 gene causing type-1 long QT syndrome $[15,16]$ and in the human ether-a-gogo-related gene (HERG) causing type-2 long QT syndrome [17]. Mutations involving the KCNQ1 gene result in reduction of the slow component of the delayed rectifier repolarizing current $I_{\mathrm{KS}}$, HERG mutations have been found to be associated with reduction of the rapid component of this current $I_{K r}$, and both contribute to lengthening of the QT interval $[15,18]$. In humans the KCNQ1 gene is expressed in kidneys, placenta, lungs and heart. The highest mRNA transcript levels of the KCNQ1 gene have been observed in heart muscle cells; no expression was found in brain, skeletal muscles or liver [19, 20]. The $\mathrm{KCNH} 2$ gene was shown to be important in preventing premature heart stimulation [21, 22].

The aim of this study was to answer the question how the expression of genes encoding slow and fast potassium channels, KCNQ1 and HERG, respectively, changes depending on age and gender of the patient.

\section{Material and methods}

Gene expression was studied in subjects from unrelated families; initial diagnoses were based on such clinical features as altered ECG and echocardiography. One hundred sixty-three patients from the Paediatric Cardiology Department of the Medical University of Silesia in Katowice-Ligota were enrolled in the study, including 98 with clinically diagnosed (ECG) LQTS. Type 1 LQTS was diagnosed in 60 patients and type 2 LQTS in 38 patients. The remaining 65 patients were healthy individuals without clinically confirmed LQTS symptoms; these individuals were from 43 families whose members were diagnosed with the long QT syndrome. The principal goal of this study was to examine the expression of KCNQ1 and HERG genes that are responsible for the occurrence of LQTS1 and LQTS2. Additionally, the study attempted to answer the question whether and how the expression of the examined genes depends on patients' age and gender. The study also attempted to verify whether $\beta$-actin is a good endogenous control for determining the expression of the studied genes.

\section{Total RNA extraction}

Total RNA extraction was performed using Fenozol total RNA isolation Reagent Set (A\&A Biotechnology). Consent to use blood samples taken from patients was obtained from the Bioethics Committee of the MUS in Katowice.

\section{QRT-PCR}

Assessment of transcriptional activity of the investigated genes was carried out using commercial kits (TaqMan Gene Expression Assays Applera for KCNQ1 gene inventoried set 4331182 Hs00165003m1 - length of PCR product $78 \mathrm{bp}$; for HERG gene inventoried set $4331182 \mathrm{Hs} 00542478 \mathrm{~m} 1$ - length of PCR product $82 \mathrm{bp}$ ). The number of mRNA copies of the investigated genes was determined based on kinetics of the QRT-PCR reaction using an $A B I$ PRISM ${ }^{\text {TM }} 7000$ sequence detector (Applied Biosystems, CA, USA) and a ROX QuantiTect Probe RT-PCR kit containing a fluorescent dye. QRT-PCR was carried out in one step. The reaction mix contained $10 \mu \mathrm{l} 2 \times$ QuantiTect Probe RT-PCR Master Mix, $0.1 \mu l$ QuantiTect RT Mix (Qiagen $\mathrm{GmbH}$, Germany) and $1 \mu \mathrm{lmix}$ of TaqMan Gene Expression Assay starters and probes (Applied Biosystems), RNA matrix and pyrogen-free water. The reaction mix to amplify $\beta$-actin gene DNA standards contained $25 \mu \mathrm{l} 2 \times$ QuantiTect Probe RT-PCR Master Mix (Qiagen GmbH, Germany) and $0.5 \mu \mathrm{M}$ sense and antisense starters, $\beta$-actin cDNA template and pyrogen-free water (Applied Biosystems TaqMan Gene Expression Assays for AKT 4331182 Hs 99999903 m1). The reverse transcription reaction (in two repeats) was carried out at $50^{\circ} \mathrm{C}$ for 30 min. Following initial activation of HotStar Taq DNA Polymerase $\left(95^{\circ} \mathrm{C} / 15 \mathrm{~min}\right)$, a two-step reaction was carried out including denaturation at $94^{\circ} \mathrm{C}$ for $15 \mathrm{~s}$ and starter annealing at $60^{\circ} \mathrm{C}$ for $60 \mathrm{~s}$ (40 cycles). Final elongation of amplification products was carried out at $72^{\circ} \mathrm{C}$ for $10 \mathrm{~min}$. To confirm the absence of non-specific amplification, the PCR products were analysed by polyacrylamide gel electrophoresis and sequence analysis (ABIPRISM377).

\section{Statistical analysis}

Expression level of the investigated genes was inferred from the analysis of the number of mRNA copies per $1 \mu \mathrm{g}$ total RNA. The data were exported from an Excel datasheet to the STATISTICA v.7.1 data analysis software system (StatSoft Inc. 2006). Descriptive statistics were computed including median, standard deviation and average values. The degree of normality was examined with the Shapiro-Wilk test. Due to the lack of normal distribution of the investigated parameters, we used a non-parametric test (Mann-Whitney $U$-test) to analyse the results from the experimental and control groups. The statistical significance level was set at $p<0.05$.

\section{Results}

A series of QRT-PCR reactions was performed. The electrophoretic evaluation of amplimers (length of PCR product for KCNQ1 gene - $78 \mathrm{bp}$; for HERG 
gene $-82 \mathrm{bp}$ ) and sequence analysis confirmed the specificity of the performed QRT-PCR reaction (data not shown). The results are expressed as the number of mRNA copies of the analysed genes per $1 \mu \mathrm{g}$ of total RNA. We have determined $\beta$-actin mRNA copy number in all analysed groups. The $\beta$-actin mRNA copy numbers were not statistically different between control and affected groups and may be a good endogenous control for determining the expression of the studied genes.

Significantly lower KCNQ1 and KCNH2 mRNA levels in healthy females than healthy males were observed (Mann-Whitney $U$ test, $p=0.032$; $p=0.02$; Figure 1), whereas in male patients both transcripts were expressed at a lower level than in female patients (Mann-Whitney $U$ test, $p=0.0084$; $p=0.035$; Figure 2). The comparison of transcriptional activity of $\mathrm{KCNQ} 1$ and $\mathrm{KCNH} 2$ genes in healthy adults and children revealed considerably higher KCNQ1 and lower KCNH2 mRNA levels in

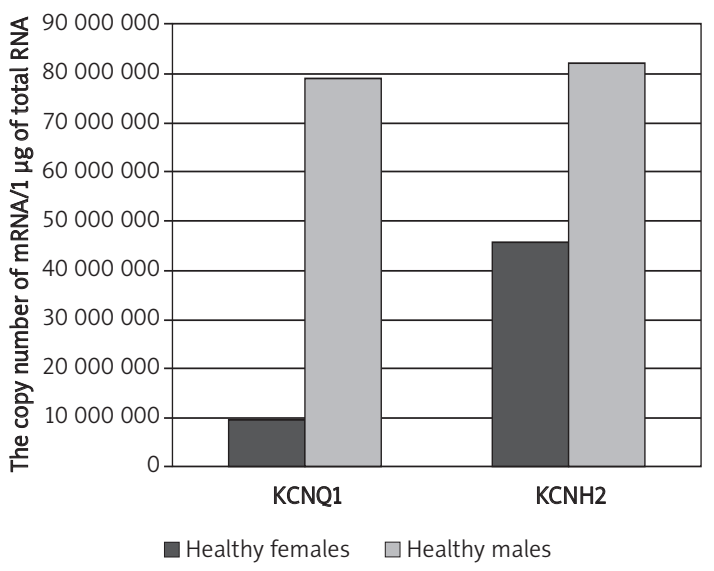

Figure 1. Comparison of KCNQ1 and KCNH2 mRNA levels between healthy females and males. Results are expressed as copy numbers per $1 \mathrm{\mu g}$ of total RNA

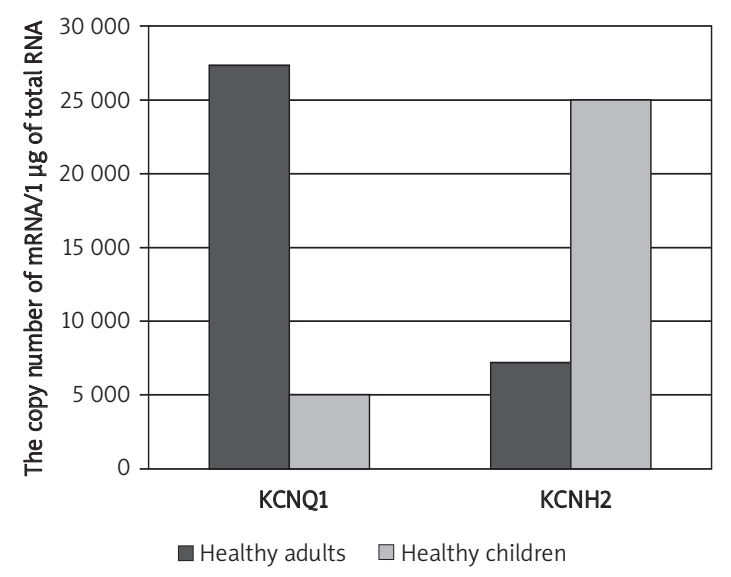

Figure 3. Comparison of KCNQ1 and KCNH2 mRNA levels between healthy adults and healthy children. Results are expressed as copy numbers per $1 \mu \mathrm{g}$ of total RNA healthy adults (Mann-Whitney U test, $p=0.033$; $p=0.04$; Figure 3).

We have also compared KCNQ1 and $\mathrm{KCNH} 2$ mRNA copy numbers in patient groups divided into subgroups based on their age (adults - age below 55 years and over 55 years; children - age below 15 and over 15 years). This analysis showed remarkably higher KCNQ1 and lower KCNH2 mRNA levels in adult patients below 55 years old than in adults over 55 years old (Mann-Whitney $U$ test, $p=0.036 ; p=0.044$; Figure 4).

Moreover, significantly higher KCNQ1 and lower $\mathrm{KCNH} 2 \mathrm{mRNA}$ levels were detected in adult patients (age over 55 years) than in paediatric patients (age below 15 years) (Mann-Whitney $U$ test, $p=0.047 ; p=0.08$; Figure 5).

\section{Discussion}

The existence of differences in heart rhythm disorders in women compared to men has been

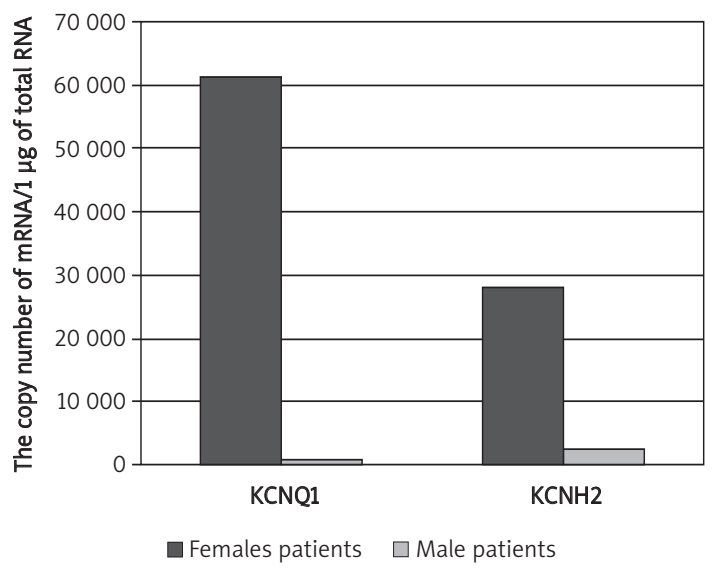

Figure 2. Comparison of KCNQ1 and KCNH2 mRNA levels between female and male patients. Results are expressed as copy numbers per $1 \mu \mathrm{g}$ of total RNA

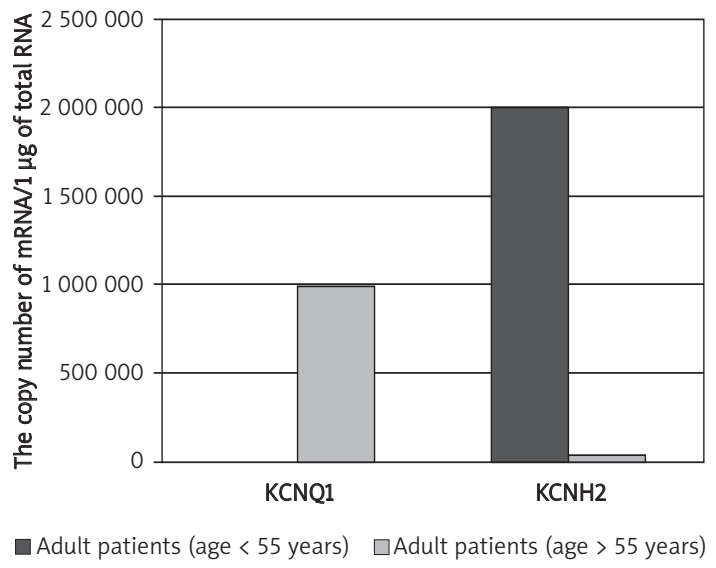

Figure 4. Comparison of KCNQ1 and $\mathrm{KCNH} 2$ mRNA levels between adults patients (age $>55$ years and age $<55$ years). Results are expressed as copy numbers per $1 \mu \mathrm{g}$ of total RNA 


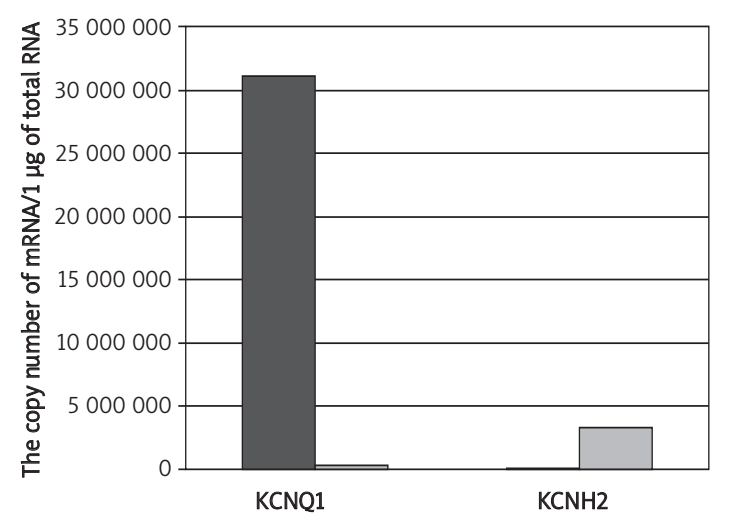

Adult patients (age $>55$ years) $\quad \square$ Children patients (age $<15$ years)

Figure 5. Comparison of KCNQ1 and $\mathrm{KCNH} 2 \mathrm{mRNA}$ levels of adult patients (age $>55$ years) and paediatric patients (age $<15$ years). Results are expressed as copy numbers per $1 \mu \mathrm{g}$ of total RNA

known at least since 1996, when Burke et al. [23] described electrocardiographic changes in the form of prolonged QT duration, higher incidence of sinus rhythm at rest, and the tendency to recurrent nodal tachycardia or a medication-induced ventricular tachycardia torsades de pointes (TdP) [24]. In women, a prolonged QT interval (also corrected), on average by 10-20 ms compared to that of men, and shorter QT dispersion have been confirmed [25, 26]. There has also been proven higher incidence of complications and pro-arrhythmic effect of various drugs such as antihistamines, antibiotics (erythromycin), antiarrhythmics (sotalol), antidepressants and others. The ability of these drugs to block potassium channels suggests still undefined dysfunction of these channels in women [27, 28]. The studies of Rautaharju et al. [29] have also confirmed that the QTc interval is longer in women than in men aged 15-55 years, while no differences were observed in corrected QTc duration in children up to 15 years old and adults over 55 years old. There are several explanations for the mechanisms responsible for QT prolongation and a tendency to arrhythmia in women. These include very low level of androgens with their protective effect and consequently decreased QTC as opposed to men, genetically based differences in the density of potassium channels in the cell membrane of myocardial cells, modulating effects of oestrogens on the function and kinetics of potassium and calcium channels, modulating the expression of ion channels [30-34], and prolongation of QTc as well as dominance of the parasympathetic system favouring the extension of the QT [35-37]. The study by Liu et al. [32] suggests low expression of genes encoding potassium channels in female rabbit myocardium cells compared with male rabbits (density of potassium channels lower by $20 \%$, cellular Ik1 potassium currents lower by $14 \%$ ). Besides the differences in the duration of the $\mathrm{OT}$ interval between women and men, also differences in the dynamics of adaptation of QT duration to heart rate changes, as well as differences in the morphology of ST-T segments have been observed. They result from lower heart muscle weight, dissimilar thorax configuration and probably different ionic structure of cell membrane of heart muscle in women compared to men [32, 38]. Further studies revealed that among patients reported to the international registry of patients with CLQTS women constituted $70 \%$ of the probands $[4,5,31,39,40]$. Moss et al. [41] have proposed criteria for diagnosis of QT prolongation specific to gender and age of the test: for children aged 0-15 years the volume of QTC > 0.46, for men $>16$ years greater than 0.45 , and females QTC $>0.46[9,41,42]$. We here aimed at assessing the effects of KCNQ1 and $\mathrm{KCNH} 2$ gene expression level on the occurrence of long QT interval syndrome. To our knowledge, this is the first study that examines KCNQ1 and HERG gene expression in human patients. The rather unique character of this study results from comparing the expression levels of KCNQ1 and $\mathrm{KCNH} 2$ genes in subjects with clinically diagnosed LQT1 and LQT2 syndromes and in healthy subjects. The present study is also the first to use patients' peripheral blood as the material for the subject investigation. Studies on KCNQ1 and HERG expression reported so far were based on animal biopsy material or commercially available cell lines. We have found significantly lower KCNQ1 and $\mathrm{KCNH} 2$ mRNA levels in healthy females than in healthy males and significantly lower KCNQ1 and $\mathrm{KCNH} 2$ mRNA levels in male patients compared with female patients. These findings suggest that the higher male risk related to acquired cardiovascular disorders in the unaffected population is counterbalanced in the affected population by higher female risk related to the genetic disorder [43]. Previous studies have suggested that the rate of increase in cardiac events generally plateaus in adult males [4, 9]. Event manifestations specifically in LQT1 and LQT2 patients might be modulated differently by age and gender [9, 44]. Preliminary studies suggest that a pro-arrhythmic response may be genetically determined as a result of mutations or polymorphisms in genes encoding ion channels in heart muscle cells [31]. The incidence of lifethreatening events was lower among LQT1 patients compared to the other genotypes, partly because of the high prevalence of silent mutation carriers [QTc, $440 \mathrm{~ms}$ ]; the risk was higher among LQT2 females vs. males and LQT3 males vs. females [45]. We have also compared KCNQ1 and KCNH2 mRNA copy numbers between healthy adults and healthy children and found significantly higher KCNQ1 and lower $\mathrm{KCNH} 2$ mRNA levels in healthy adults compared to healthy children. The risk of arrhythmic 
complications in patients with long QT syndrome also varies according to sex, age and genotype. In LQT1 syndrome caused by mutation of the KCNQ1 gene, the risk is increased in boys before 15 years of age and in adult females is higher than in men. In the LQT2 syndrome caused by mutation in the HERG gene a preponderance of arrhythmic complications risk in girls could be observed but it is very visible in adult women $[4,9,10]$. Comparative analysis of KCNQ1 and KCNH2 mRNA copy numbers in patients divided into subgroups based on age (adults - age below 55 years and over 55 years; children - age below 15 and over 15) in the present study showed significantly higher KCNQ1 and lower KCNH2 mRNA levels in adult patients (age over 55 years) than in adult patients (age below 55 years). Children are typically affected and more than $50 \%$ of the patients have experienced their first episode of syncope or cardiac arrest by the age of 15 years [10, 46, 47]. A few additional findings emphasized high risk for first cardiac events during adolescence, with girls experiencing an increased risk compared with boys, a crossover in risk by sex at approximately age 13 years, and a lower rate of first cardiac events in the adult years than in the younger years $[4,5,11,48]$. LQT1 children were considered as a low-risk group compared to LQT2 or LQT3 mutation carriers, especially under beta blocker therapy [46, 49]. In 2008 Goldenberg et al. [43] suggested that the subjects who are affected with this CLQTS and survive to age 40 years have a relatively lower risk of experiencing disease-related fatal or near fatal arrhythmic events than their younger counterparts. It is also possible that the increasing prevalence of other forms of cardiac and non-cardiac acquired disease processes may dominate mortality risk in the older age group. In our study adult patients (age over 55 years) presented significantly higher KCNQ1 and lower KCNH2 mRNA levels than paediatric patients (age below 15 years). Gender and age also play significant roles in influencing the clinical course of LQTS in that cardiac events tend to occur more frequently in children, with males having an increased risk of events during pre-adolescence and females having higher event rates in adolescence and beyond [4]. Although many LQTS patients develop symptoms during adolescence, some of them experience the first cardiac event in their adulthood [50]. The mechanism of interaction between KCNQ1 and HERG genes is not simple. It has been reported that KCNQ1 coexpression modulates HERG function by enhancing membrane expression of HERG, and that the 2 proteins co-immunoprecipitate, and colocalize in myocytes. In vivo studies in genetically modified rabbits also support a HERG-KCNQ1 interaction [51]. Trafficking-competent KCNQ1 variably influences the function of HERG long QT alleles.
Otherwise the KCNQ1 gene product can form heteromultimers with two other potassium channel proteins, KCNE1 and KCNE3, and interact with CALM. In turn, HERG transcript variants encoding distinct isoforms have been identified. Isoform 3 has no channel activity by itself, but modulates channel characteristics when associated with isoform 1. It is also reported that KCNQ1 and HERG share unique interactions with KCNE1, 2 and 3 subunits. KCNE1 (IsK or MinK) recapitulates IKs when associated with KCNQ1, whereas it augments the amplitude of an IKr-like current when co-expressed with HERG [52]. Recent studies have led to the discovery of microRNAs (miRNAs) as a new player in cardiac excitability by fine-tuning expression of ion channels, transporters, and cellular proteins, which determines the arrhythmogenicity in many conditions. A single mRNA may regulate the expression of many genes with similar functions and modulate the complex picture of the phenotype or disease activity. The excess may also play a role in the paradoxical increase in target gene expression. It was stated that the following participate in cardiac function of micro RNA: mir-1, mir-133 (arrhythmias), mir-21, mir-195 (cardiac hypertrophy), mir-208 (contractility of the heart muscle) [53-55]. Disorders of epigenetic mechanisms of gene regulation may also be the cause of many monogenic and complex diseases. Epigenetics is one of the fastest growing fields of genetics: studies of variation that is not dependent on the primary DNA sequence and the results from the action of specific regulatory mechanisms (DNA methylation, modification of histone proteins, expression of antisense RNA or RNAi) [56]. As the concept of phenotypic heterogeneity of long QT syndrome was postulated and confirmed, the idea had been looming that modifier genes had to exist. Swartz et al. in 2006 currently making a specific effort towards the identification of modifier genes, not only for the duration of QT interval but also, even more, for the clinical severity of LQTS. This research group has identified a first modifier gene for the severity of LQTS. The practically important conclusion is that common polymorphism can amplify the consequences of rare mutations [57].

However, in the light of the results obtained herein it is suggested that gene expression profiles may be an additional criterion of differential diagnosis of LQTS types. At present this is an experimental method which may be helpful in LQTS diagnosis.

In conclusion, our results support the hypothesis that variations in KCNQ1 and HERG gene expression is influenced by age and gender in human patients with long QT syndrome and in healthy subjects. This research has been restricted to small sample numbers which limits the generalizability of its findings. A replication study for the associa- 
tion between gender and age and expression of the analysed genes needs to be performed.

\section{Acknowledgments}

The study was supported by a grant (No. N 404 038 31/2150) from the State Committee of Scientific Research (Poland).

\section{References}

1. Goldenberg I, Moss AJ, Peterson DR, et al. Risk factors for aborted cardiac arrest and sudden cardiac death in children with the congenital long-QT syndrome. Circulation 2008; 117: 2184-91

2. Vincent GM. The Long QT and Brugada syndromes: causes of unexpected syncope and sudden cardiac death in children and young adults. Semin Pediatr Neurol 2005; 12: $15-24$.

3. Moss AJ. Long QT-syndrome. JAMA 2003; 289: 2041-4.

4. Locati EH, Zareba W, Moss AJ, et al. Age- and sex-related differences in clinical manifestations in patients with congenital long-QT syndrome: findings from the International LQTS Registry. Circulation 1998; 97: 2237-44.

5. Moss AJ, Schwartz PJ, Crampton RS, et al. The long QT syndrome. Prospective longitudinal study of 328 families. Circulation 1991; 84: 1136-44.

6. Priori SG, Schwartz PJ, Napolitano C, et al. Risk stratification in the long-QT syndrome. N Engl J Med 2003; 348: 1866-74.

7. Schwartz PJ, Priori SG, Spazzolini C, et al. Genotype-phenotype correlation in the long-QT syndrome: gene-specific triggers for life-threatening arrhythmias. Circulation 2001; 103: 89-95.

8. Vincent GM, Timothy KW, Leppert M, et al. The spectrum of symptoms and QT intervals in carriers of the gene for the long-QT syndrome. N Engl J Med 1992; 327: 846-52.

9. Zareba W, Moss AJ, Locati EH, et al. International Long QT Syndrome Registry Modulating effects of age and gender on the clinical course of long QT syndrome by genotype. J Am Coll Cardiol 2003; 42: 103-9.

10. Zareba W, Moss AJ, Schwartz PJ, et al. Influence of genotype on the clinical course of the long-QT syndrome. International Long-QT Syndrome Registry Research Group. N Engl J Med 1998; 339: 960-5.

11. Moss AJ, Shimizu W, Wilde AA, et al. Clinical aspects of type-1 long-QT syndrome by location, coding type, and biophysical function of mutations involving the KCNQ1 gene. Circulation 2007; 115: 2481-9.

12. Priori SG, Bloise R, Crotti L. The long QT syndrome. Europace 2001; 3: 16-27.

13. Priori SG, Cerrone M. Genetic arrhythmias. Ital Heart J 2005; 6: 241-8.

14. Wilde AA, Bezzina CR. Genetics of cardiac arrhythmias. Heart 2005; 91: 1352-8.

15. Sanquinetti MC. Long QT syndrome: ionic basis and arrhythmia mechanism in long QT syndrome type 1. J Cardiovasc Electrophysiol 2000; 11: 710-2.

16. Tester DJ, Will ML, Haglund CM, et al. Compendium of cardiac channel mutations in 541 consecutive unrelated patients referred for long QT syndrome genetic testing. Heart Rhythm 2005; 2: 507-17.

17. Moss AJ, Zareba W, Kaufman ES, et al. Increased risk of arrhythmic events in long-QT syndrome with mutations in the pore region of the human ether-a-go-go-related gene potassium channel. Circulation 2002; 105: 794-9.
18. Sanguinetti MC, Curran ME, Spector PS, et al. Spectrum of HERG K+-channel dysfunction in an inherited cardiac arrhythmia. Proc Natl Acad Sci USA 1996; 93: 2208-12. Erratum in: Proc Natl Acad Sci USA 1996; 93: 87-96.

19. Lou X, Xiao J, Lin H, et al. Genomic structure, transcriptional control, and tissue distribution of HERG1 and KCNQ1 genes. Am J Physiol Heart Circ Physiol 2008; 294: H1371-80.

20. Markiewicz-Łoskot G, Moric-Janiszewska E, Mazurek U. The risk of cardiac events and genotype-based management of LQTS patients. Ann Noninvasive Electrocardiol 2009; 14: 86-92.

21. Jones EM, Roti EC, Wang J, et al. Cardiac IKr channels minimally comprise hERG $1 \mathrm{a}$ and $1 \mathrm{~b}$ subunits. J Biol Chem 2004; 279: 44690-4.

22. Towbin JA, Vatta M. Molecular biology and the prolonged QT syndromes. Am J Med 2001; 110: 385-98.

23. Burke JH, Goldberger JJ, Ehlert FA, et al. Gender differences in heart rate before and after autonomic blockade: evidence against an intrinsic gender effect. Am J Med 1996; 100: 537-43.

24. Khan IA. Clinical and therapeutic aspects of congential and acquired long QT syndrome. Am J Med 2002; 112: 58-66.

25. Kawasaki R, Machado C, Reinoehl J, et al. Increased propensity of women to develop torsades de pointes during complete heart block. J Cardiovasc Electrophysiol 1995; 6: 1032-8.

26. Larsen JA, Kadish AH. Effects of gender on cardiac arrhythmias. J Cardiovasc Electrophysiol 1998; 9: 655-64.

27. Ebert SN, Liu XK, Woosley RL. Female gender as a risk factor for drug-induced cardiac arrhythmias: evaluation of clinical and experimental evidence. J Womens Health 1998; 7: 547-57.

28. Lehmann MH, Hardy S, Archibald D, et al. JTc prolongation with d,l-sotalol in women versus men. Am J Cardiol 1999; 83: 354-9.

29. Rautaharju PM, Zhou SH, Wong S, et al. Sex differences in the evolution of the electrocardiographic QT interval with age. Can J Cardiol 1992; 8: 690-5.

30. Bidoggia H, Maciel JP, Capalozza N, et al. Sex differences on the electrocardiographic pattern of cardiac repolarization: possible role of testosterone. Am Heart J 2000; 140: 678-83.

31. Hreiche R, Morissette P, Turgeon J. Drug-induced long QT syndrome in women: review of current evidence and remaining gaps. Gend Med 2008; 5: 124-35.

32. Liu XK, Katchman A, Drici MD, et al. Gender difference in the cycle length-dependent QT and potassium currents in rabbits. J Pharmacol Exp Ther 1998; 285: 672-9.

33. Shimoni Y, Liu XF. Sex differences in the modulation of $\mathrm{K}_{+}$ currents in diabetic rat cardiac myocytes. J Physiol 2003; 550: 401-12.

34. Song M, Helguera G, Eghbali M, et al. Remodeling of Kv4.3 potassium channel gene expression under the control of sex hormones. J Biol Chem 2001; 276: 31883-90.

35. Drici MD, Burklow TR, Haridasse V, et al. Sex hormones prolong the QT interval and downregulate potassium channel expression in the rabbit heart. Circulation 1996; 94: 1471-4

36. Larsen JA, Tung RH, Sadananda R, et al. Effects of hormone replacement therapy on QT interval. Am J Cardiol 1998; 82: 993-5.

37. Sbarouni E, Zarvalis E, Kyriakides ZS, et al. Absence of effects of short-term estrogen replacement therapy on resting and exertional QT and QTc dispersion in postmenopausal women with coronary artery disease. Pacing Clin Electrophysiol 1998; 21: 2392-5. 
38. Kligfield P, Lax KG, Okin PM. QT interval-heart rate relation during exercise in normal men and women: definition by linear regression analysis. J Am Coll 1996; 28: 1547-55.

39. Hashiba K. Sex differences in phenotypic manifestation and gene transmission in the Romano-Ward syndrome. Ann N Y Acad Sci 1992; 644: 142-56.

40. Kaab S, Pheufer A, Hinterseer M, et al. Long QT syndrome. Why does sex matter? Z Kardiol 2004; 93: 641-5.

41. Moss AJ, Robinson J. Clinical features of the idiopatic long QT syndrome. Circulation 1992; 85 (Suppl I): I140-4.

42. Goldenberg I, Zaręba W, Moss AJ. Long QT syndrome. Curr Probl Cardiol 2008; 33: 629-94.

43. Goldenberg I, Moss AJ, Bradley J, et al. Long-QT syndrome after age 40. Circulation 2008; 117: 2192-201.

44. Sauer AJ, Moss AJ, McNitt S, et al. Long QT syndrome in adults J Am Coll Cardiol 2007; 49: 329-37.

45. Crotti L, Celano G, Dagradi F, et al. Congenital long QT syndrome. Orphanet J Rare Dis 2008; 7: 18.

46. Wedekind H, Burde D, Zumhagen S, et al. QT interval prolongation and risk for cardiac events in genotyped LQTS-index children. Eur J Pediatr 2009; 168: 1107-15.

47. Zareba W. Genotype-specific ECG patterns in long QT syndrome. J Electrocardiol 2006; 39 (4 Suppl): S101-6.

48. Hobbs JB, Peterson DR, Moss AJ, et al. Risk of aborted cardiac arrest or sudden cardiac death during adolescence in the long-QT syndrome. JAMA 2006; 296: 1249-54.

49. Etheridge SP, Sanatani S, Cohen MI, et al. Long QT syndrome in children in the era of implantable defibrillators. J Am Coll Cardiol 2007; 50: 1335-40.

50. Sakaguchi T, Shimizu W, Itoh H, et al. Age- and genotypespecific triggers for life-threatening arrhythmia in the genotyped long QT syndrome. J Cardiovasc Electrophysiol 2008; 19: 794-9.

51. Hayashi K, Shuai W, Sakamoto Y, Higashida H, Yamagishi $M$, Kupershmidt S. Trafficking-competent KCNQ1 variably influences the function of HERG long QT alleles. Heart Rhythm 2010; 7: 973-80.

52. Tinel N, Diochot S, Borsotto M, Lazdunski M, Barhanin J. KCNE2 confers background current characteristics to the cardiac KCNQ1 potassium channel. EMBO J 2000; 19: 6326-30.

53. Wang Z. The role of microRNA in cardiac excitability. J Cardiovasc Pharmacol 2010; 56: 460-70.

54. Huang ZP, Neppl RL, Wang DZ. MicroRNAs in cardiac remodeling and disease. J Cardiovasc Transl Res 2010; 3 : 212-8.

55. Luo X, Zhang H, Xiao J, Wang Z. Regulation of human cardiac ion channel genes by microRNAs: theoretical perspective and pathophysiological implications. Cell Physiol Biochem 2010; 25: 571-86.

56. Egger G, Liang G, Aparicio A, Jones PA. Epigenetics in human disease and prospects for epigenetic therapy. Nature 2004; 429: 457-63.

57. Schwartz PJ. The congenital long QT syndromes from genotype to phenotype: clinical implications. J Intern Med 2006; 259: 39-47. 